\title{
Anticipating the induced delamination formation in composite laminates subjected to bending loads
}

\author{
Mohammad Bahrami ${ }^{1}$, Mohsen Malakouti ${ }^{1}$, and Amin Farrokhabadi ${ }^{1}$ \\ ${ }^{1}$ Tarbiat Modares University
}

April 10, 2021

\begin{abstract}
In this research, the effects of induced delamination on the variation of the mechanical properties of composite laminates subjected to bending loads are investigated using a micromechanical model. For this purpose, the variation of the mechanical properties of delaminated laminates is determined using stress analysis of damaged ply and classical laminate theory (CLT) relationships. Using the proposed model and CLT, the fracture toughness due to induced delamination formation is presented in cross-ply laminates. Subsequently, the variation of strain energy release rate (SERR) is calculated in terms of crack density using analytical and finite element models to detect dominant failure modes in different crack densities. The results are compared with those of matrix cracking propagation. The results obtained by the proposed analytical model are in good agreement with those obtained by existing numerical and experimental approaches. The proposed model can be utilized to predict induced delamination formation in composite laminates subjected to bending loads.
\end{abstract}

\section{Hosted file}

FFEMS2.pdf available at https://authorea.com/users/407014/articles/517458-anticipating-theinduced-delamination-formation-in-composite-laminates-subjected-to-bending-loads 